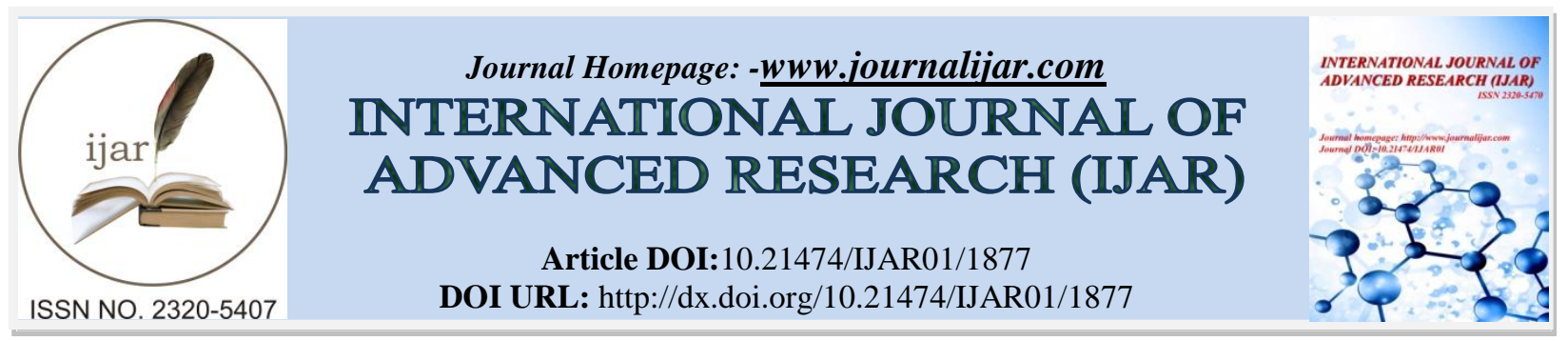

RESEARCH ARTICLE

\title{
CONVERSION OF METHANOL TO HYDROCARBONS OVER METAL MODIFIED ZSM-5 CATALYST.
}

\section{A. O. Kedia*}

1. Guru Gobind Singh Indraprastha University, New Delhi-110078, India.

Manuscript Info
Manuscript History
Received: 16 August 2016
Final Accepted: 22 Septe
Published: October 2016
Key words:-
Methanol to Hydrocarbons,
Methanol to Olefins,
Methanol to Gasoline,
Zeolite, ZSM-5,
Metal impregnation

\section{Abstract}

Renewable and alternative sources for fuel and petrochemicals are to be developed to meet the growing need of mankind. Methane can be easily obtained from renewable sources which can be converted into gasoline and olefins via methanol. This study uses zeolite catalyst (ZSM-5) and its modification by different metals to convert methanol to hydrocarbons (MTH). Catalysts are studied for their performance in the MTH reaction at $723 \mathrm{~K}$. Modified ZSM-5 catalysts are characterized by XRD and SEM. It was found that ZSM-5 catalyst modified by metals can give better results.

Copy Right, IJAR, 2016,. All rights reserved.

\section{Introduction:-}

Synthesis gas is obtained from various sources like coal, natural gas or biomass and industrial waste. Synthesis gas can be used as a raw material for the production of methanol which can be further used as a raw material for the production of hydrocarbons of gasoline range. Among various catalysts ZSM-5 is believed to be one of the most qualified catalysts for industrial applications due to its high resistance to deactivation by coke deposition, high surface area, acidic nature and well defined pore structure [1-5]. Methanol to olefins (MTO); methanol to gasoline (MTG); and methanol to propene (MTP) are developed commercially [6].

Several workers have studied the effect of different metals on product selectivities and reported different metals for increasing the selectivity of different products. HZSM-5, Al/ZSM-5, Ca/ZSM-5, Cr/ZSM-5, Cu/ZSM-5, Li/ZSM-5, Mg/ZSM-5 and Ni/ZSM-5 zeolite catalysts were studied and Cu/ZSM-5 produced the highest light olefins selectivity [7]. When activity of ZSM-5 was modified by the addition of $\mathrm{Ca}, \mathrm{Mn}, \mathrm{Cr}, \mathrm{Fe}, \mathrm{Ni}, \mathrm{Ag}, \mathrm{Ce}$ and $\mathrm{P}$, the highest selectivity of propylene was obtained over the Mn/H-ZSM-5 catalyst [8]. A series of RE/HZSM-5 catalysts, containing 7.54\% RE ( $\mathrm{RE}=\mathrm{La}, \mathrm{Ce}, \mathrm{Pr}, \mathrm{Nd}, \mathrm{Sm}, \mathrm{Eu}$ or $\mathrm{Gd}$ ), were prepared by the impregnation of the ZSM-5. Ce/HZSM-5 gave the highest yield of total olefins, and Nd/HZSM-5 gave the highest yield of propene [9]. A review of earlier researches is given in detail by stocker [10].

While several metals are studied by different workers, we found that lead impregnated ZSM-5 has not been studied so far. We have therefore chosen to compare lead with silver and copper in this study.

Corresponding Author:-A. O. Kedia.

Address:-Guru Gobind Singh Indraprastha University, New Delhi-110078, India. 


\section{Experimental:-}

Catalyst preparation:-

The ZSM-5(purchased from SudChemie) having Si/Al ratio 80 (Z80) was mixed with Metal Nitrate solution in required quantity to obtain 4 weight percent metal oxide in final samples. Samples were kept in oven at $110^{\circ} \mathrm{C}$ for 5 $\mathrm{h}$ to remove water and then calcined at $550^{\circ} \mathrm{C}$ for $5 \mathrm{~h}$. The samples thus obtained were denoted as Me-ZSM-5. Prepared catalysts are characterized by XRD and SEM.

\section{Experimental setup:-}

Nitrogen Flow rate is kept around $25 \mathrm{ml} / \mathrm{min}$ during the experiment. Methanol flow rate is controlled by peristaltic pump around $30 \mathrm{ml} / \mathrm{hr}$. Experimental setup is shown in Fig.1. Methanol and Nitrogen are passed through preheater. Methanol is converted into vapour and then sent to reactor at pre-set temperature. Liquid and gaseous products collected from the bottom of reactor are analysed using GC.

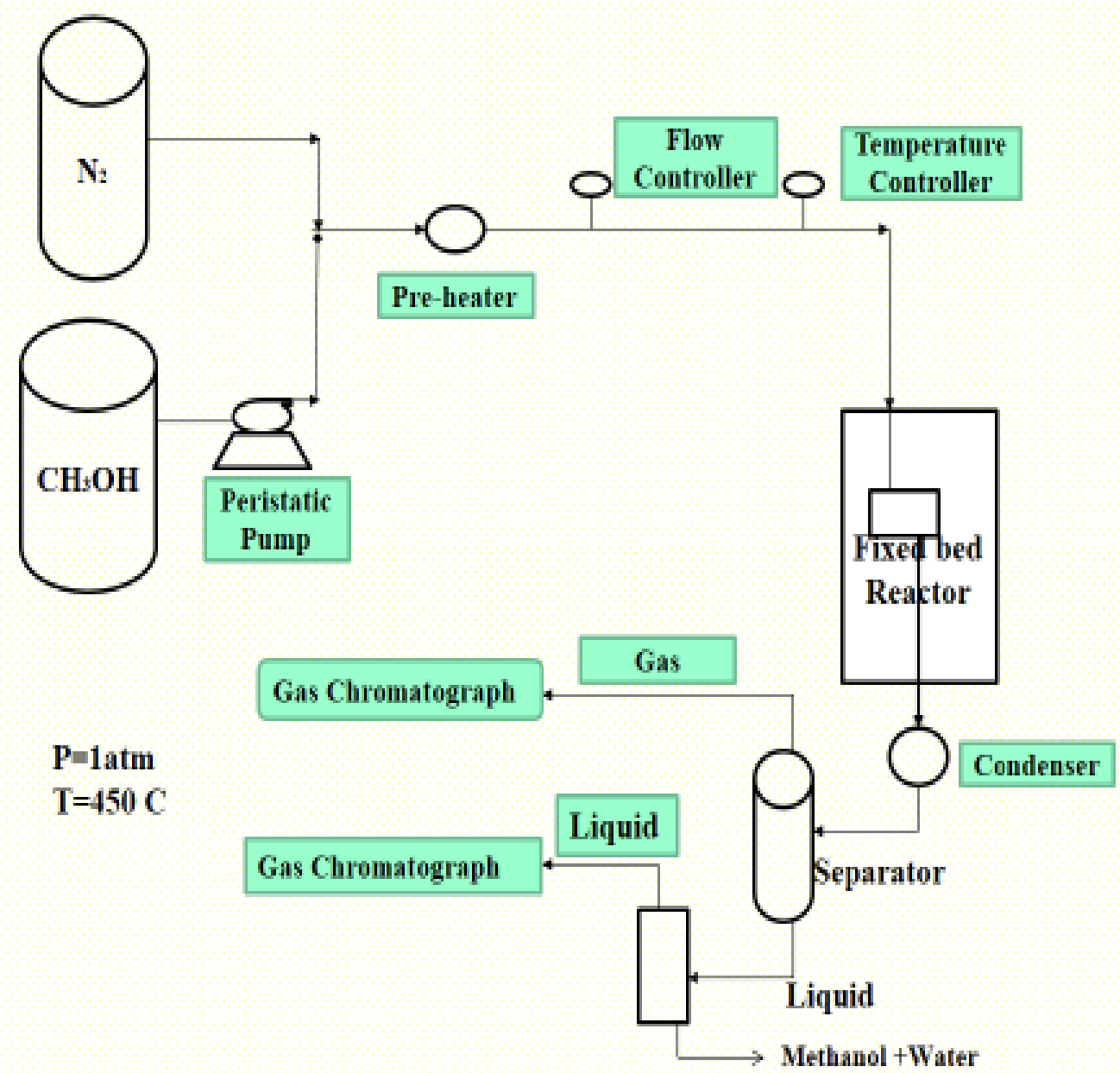

Fig 1:-Schematic Diagram of Experimental Setup.

\section{Results and Discussion:-}

XRD Analysis:-

All 4 curves in Fig. 2 are similar and have Peaks at same $2 \theta$ angle. This means that there is no change in the catalyst structure due to metal doping. Intensity of peaks have changed slightly which shows successful incorporation of metals in the catalyst. The higher intensity was observed for the starting zeolite (HZSM-5) and reduces in the order $\mathrm{Cu}, \mathrm{Ag}$ and $\mathrm{Pb}$. The decrease in the intensities can be due to higher absorption coefficient of modified catalyst. 


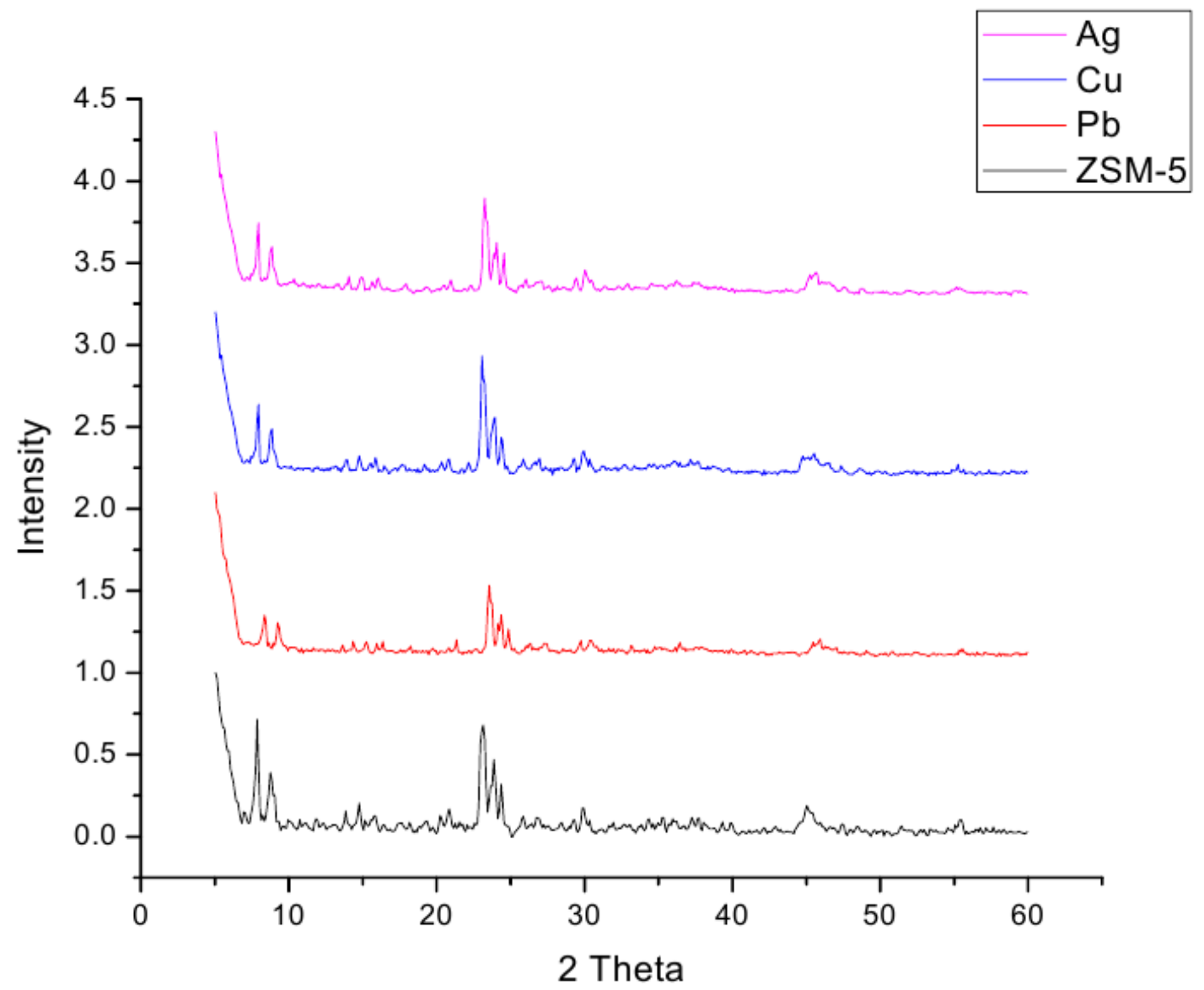

Fig. 2:- XRD patterns of ZSM-5, Pb-ZSM-5, Cu-ZSM-5 and Ag-ZSM-5 catalysts

\section{SEM Analysis:-}

The morphology of crystals, micropores and property of surface are seen by scanning electron microscopy (SEM). No significant change in the morphology after doping of metals over ZSM-5 was seen in SEM photographs of catalysts. Shape of HZSM-5 particle seems spherical from the SEM images. Fig.3-6 shows SEM images of ZSM-5 and metal impregnated zeolites. ZSM-5, Pb- ZSM-5, Cu-ZSM-5, Ag-ZSM-5 catalysts.

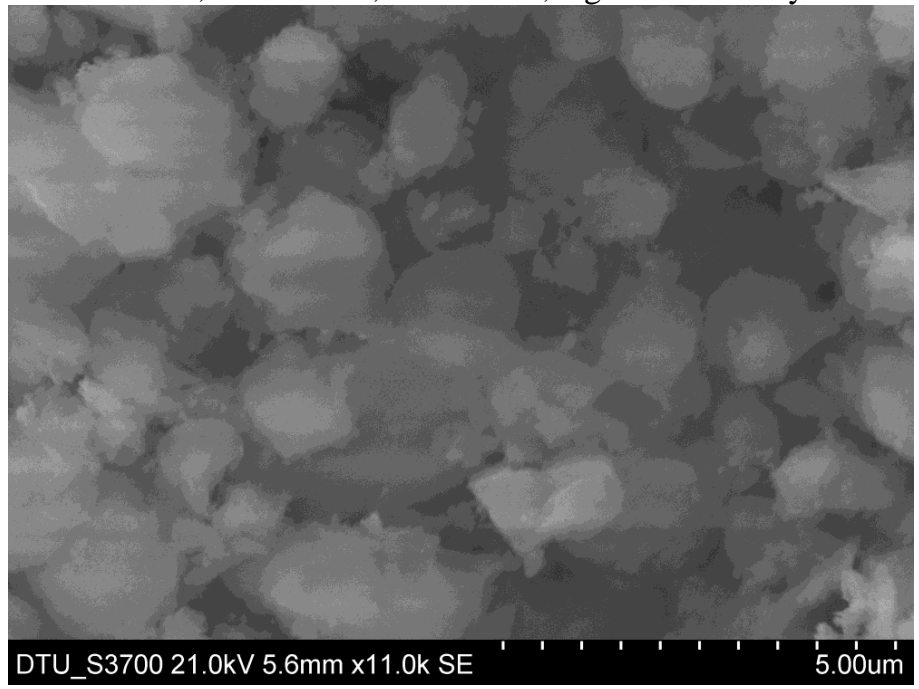

Fig 3:-SEM image for ZSM-5 


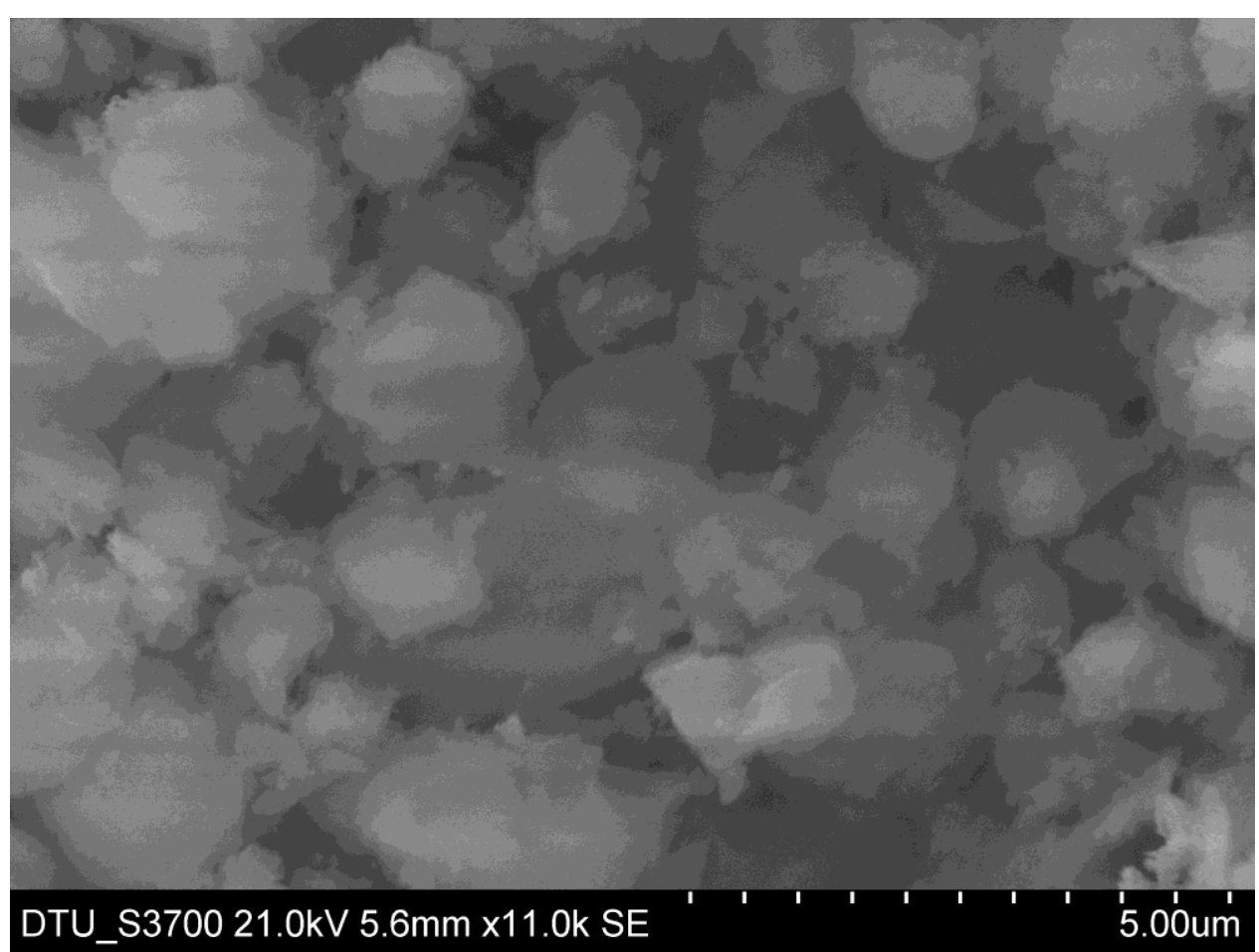

Fig 4:-SEM image for Pb-ZSM-5 catalyst.

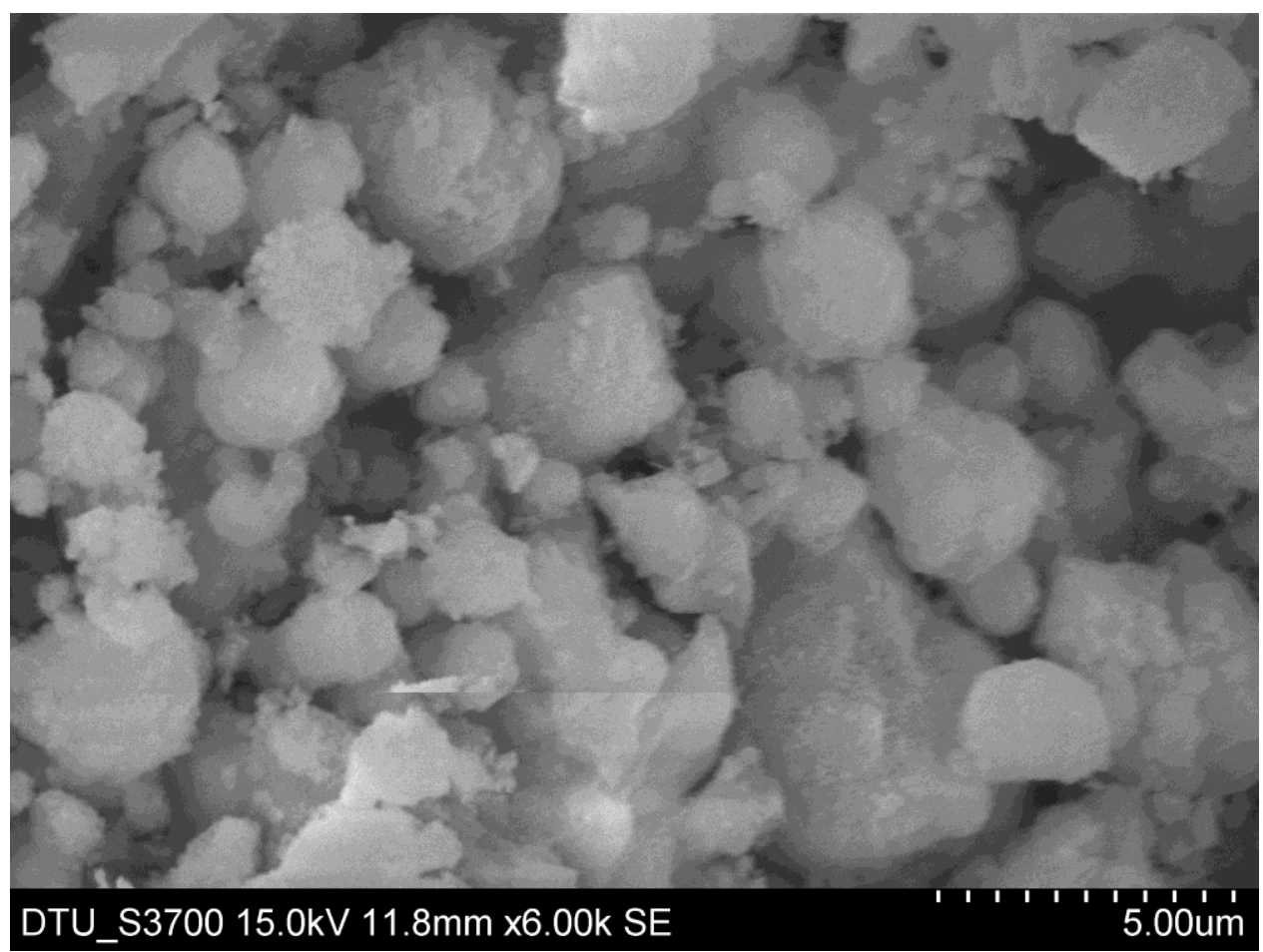

Fig 5:-SEM image for Cu-ZSM-5 catalyst. 


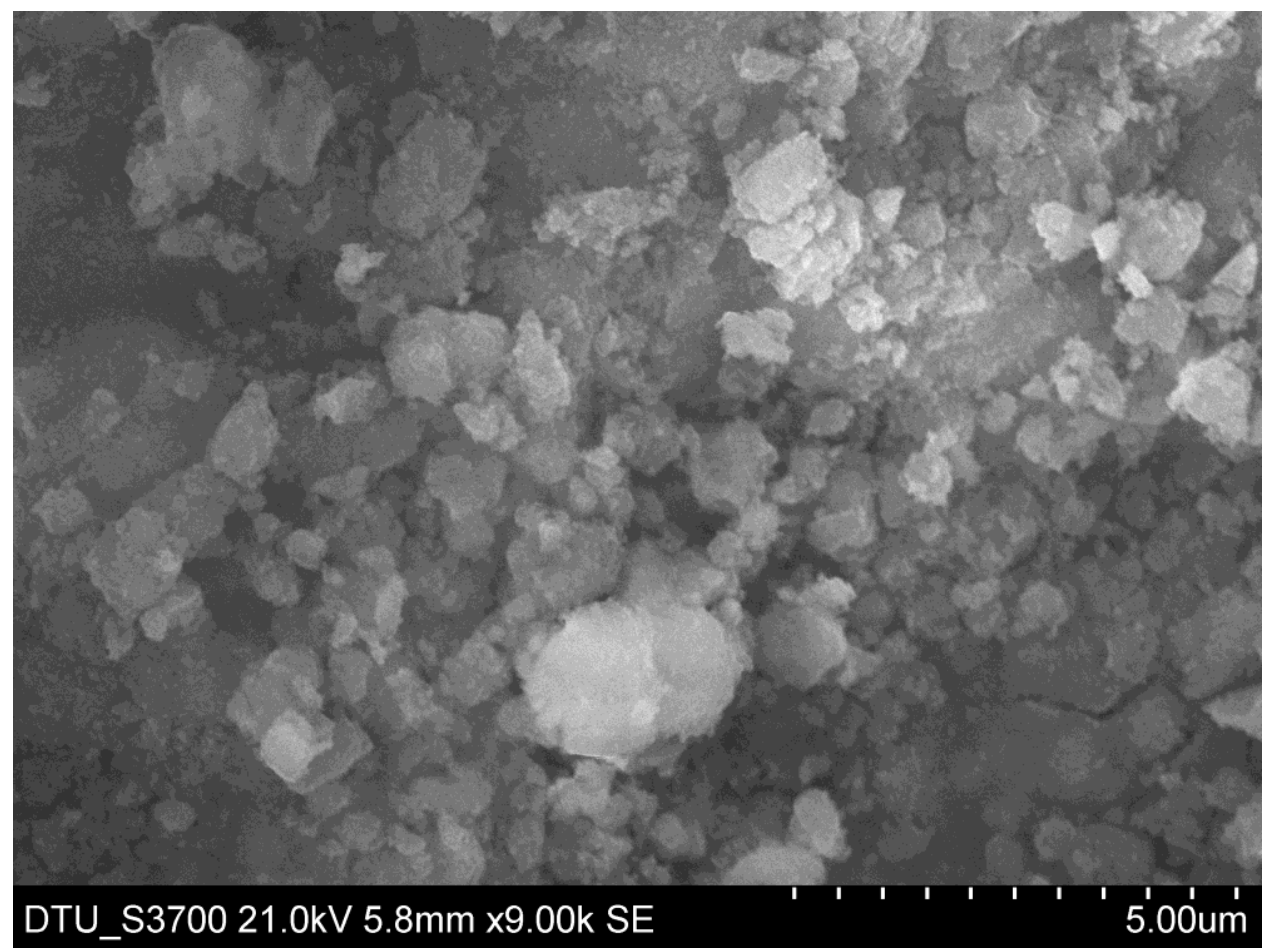

Fig 6:-SEM image for Ag-ZSM-5 catalyst

\section{Effect of Runtime on propene yield:-}

All Metal doped catalyst are showing better results in Fig. 7 as compared to parent ZSM-5. Propene yield of CuZSM-5 is nearly constant while Ag-ZSM-5 shows increase in propene with time. While Yield of ZSM-5 is increasing, it is hardly $20 \%$ of $\mathrm{Cu}$ and Ag doped catalyst. Pb-ZSM-5 on the other hand shows steep decline in propene yield. This may represent conversion of propene into higher hydrocarbons.

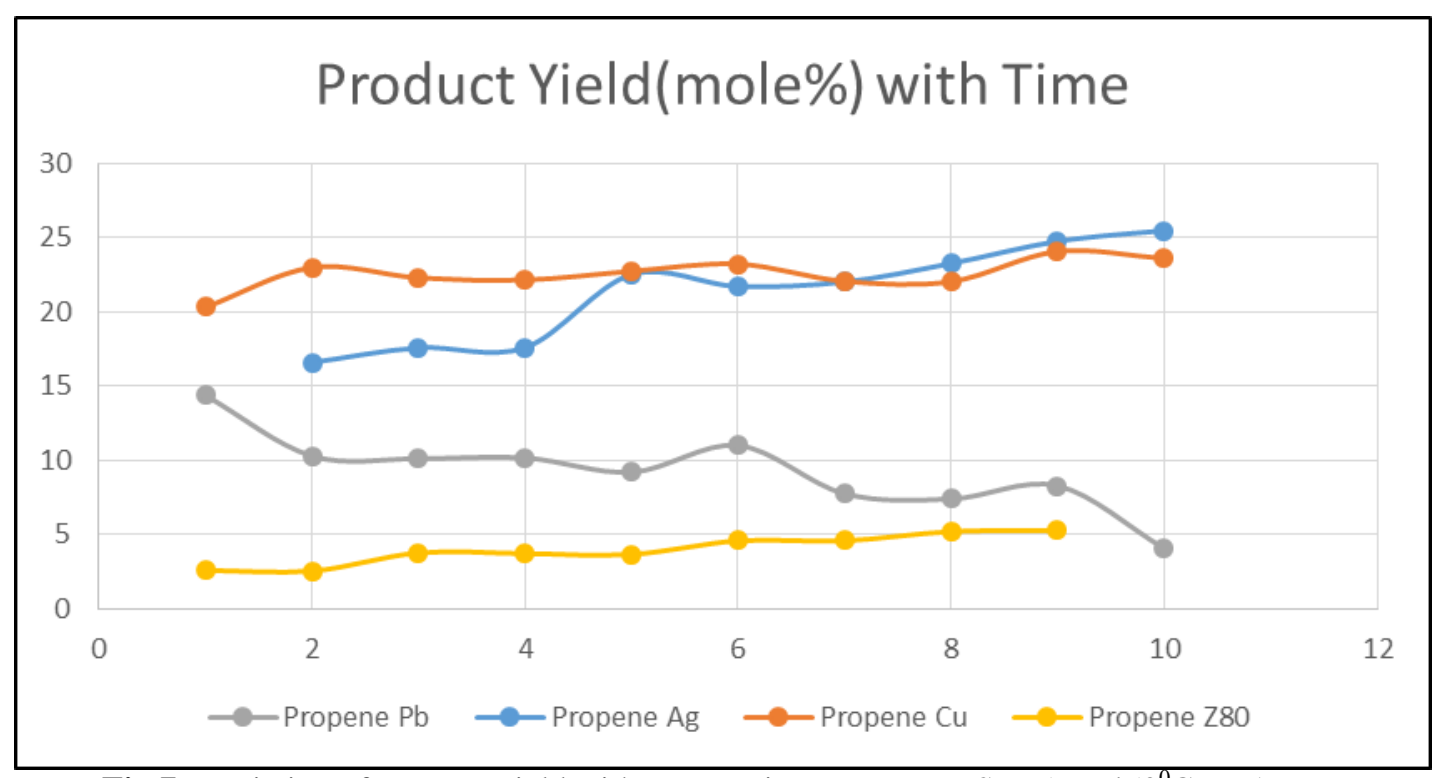

Fig 7:-Variation of propene yield with contact time over Me-ZSM-5[T=450 ${ }^{\circ} \mathrm{C}, \mathrm{P}=1 \mathrm{~atm}$, $]$ 


\section{Effect of Runtime on butene yield:-}

The increase in time of reaction results in a decrease in the yield of butene on Pb-ZSM-5 as shown in Fig.8. After 7 hours of operation, yield is reduced by nearly $65 \%$.. This means catalyst cannot be used for more time for butene production. Other catalyst show increase in butene formation.

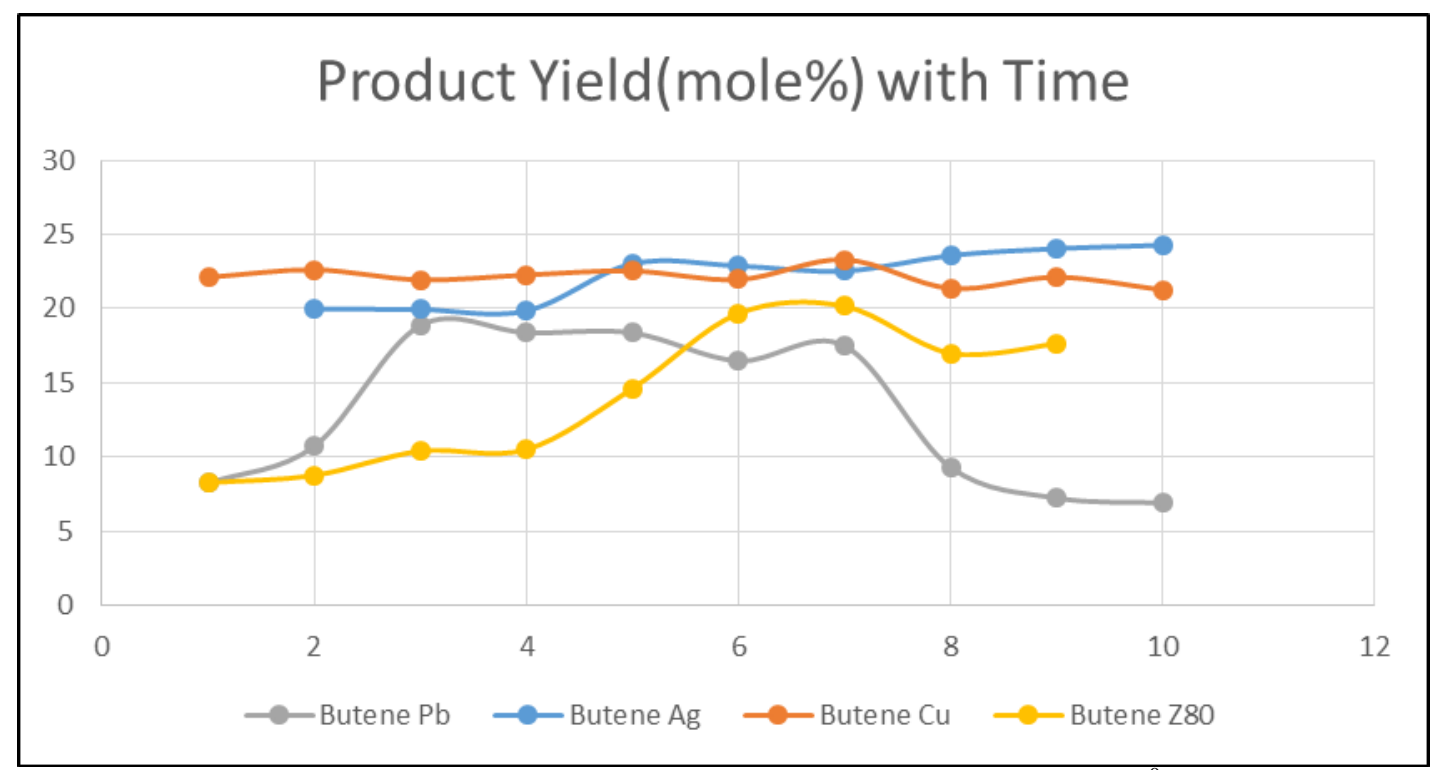

Fig 8:-Variation of butene yield with contact time over Me-ZSM-5[T=450 ${ }^{\circ} \mathrm{C}, \mathrm{P}=1 \mathrm{~atm}$, $]$

\section{Effect of Runtime on olefins yield:-}

Yield of light olefins increases with time in case of Cu-ZSM-5 and Ag-ZSM-5 as shown in Fig.9. It is nearly twice as compared to parent ZSM-5 catalyst. Decrease in light olefins for Pb-ZSM-5 is on the expected lines after 7 hours of operation as explained earlier.

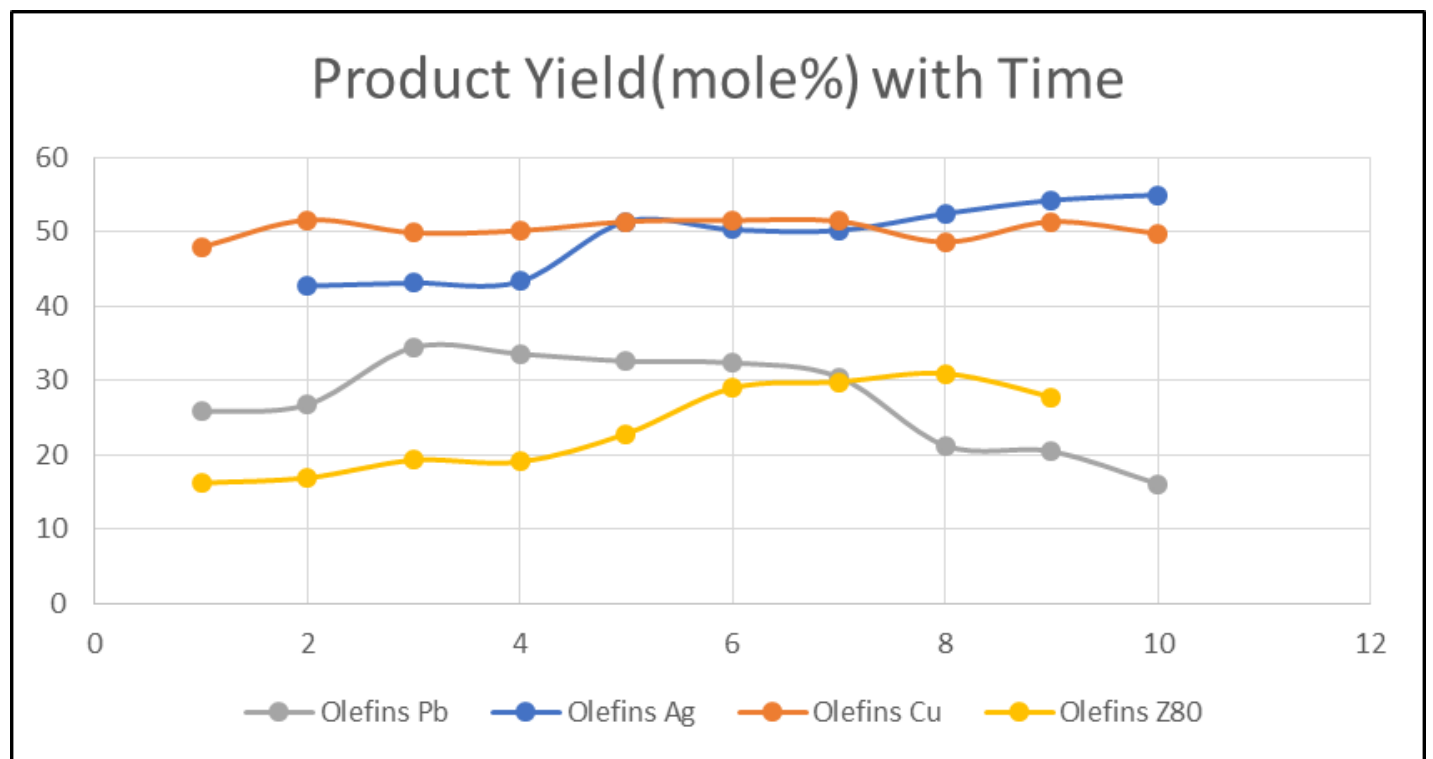

Fig 9:-- Variation of olefins yield with contact time over Me-ZSM-5[T $\left.=450^{\circ} \mathrm{C}, \mathrm{P}=1 \mathrm{~atm},\right]$

Effect of Runtime on C5plus hydrocarbon yield:-

Formation of higher hydrocarbons is negligible in case of Ag-ZSM-5 and Cu-ZSM-5 as shown in Fig. 10. A steep reduction is seen in case of parent ZSM-5 while Pb-ZSM-5 shows sudden increase after 7 hours of operation. This 
can be attributed to conversion of light olefins into higher hydrocarbons. Higher acidity of Pb-ZSM-5 is responsible for this increase. Pb-ZSM-5 catalyst is therefore suitable for the gasoline range hydrocarbons.

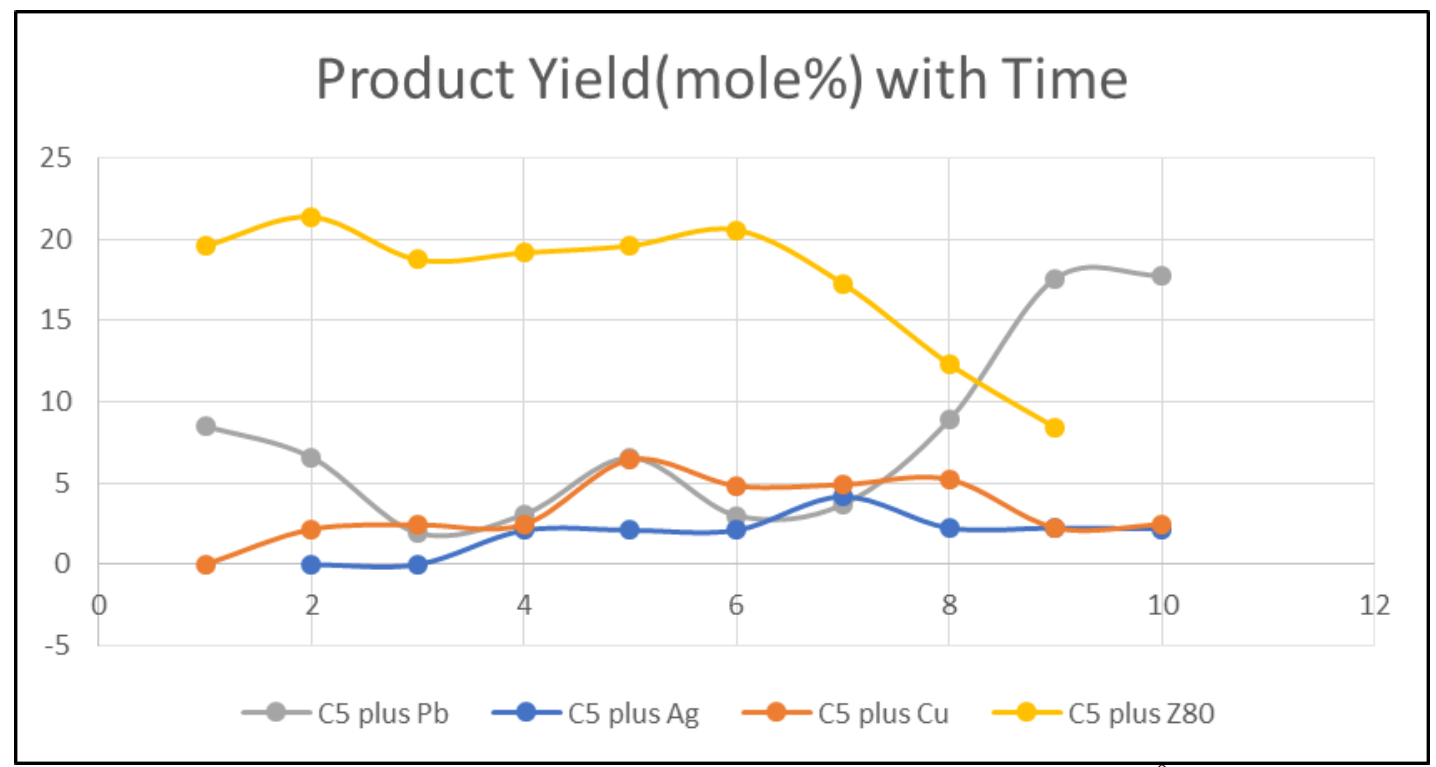

Fig10:-Variation of C5plus yield with contact time over Me-ZSM-5[T $\left.=450^{\circ} \mathrm{C}, \mathrm{P}=1 \mathrm{~atm},\right]$

\section{Conclusions:-}

The catalytic performance of metal impregnated ZSM-5 have been studied in the conversion of hydrocarbons from methanol. Light olefins yield increased progressively with time except for Pb-ZSM-5. These findings suggest that metals interact with the acid sites of ZSM-5 to reduce the strength of strong acidic sites. A significant effect on the yield of hydrocarbons was observed. Pb-ZSM-5 is the recommended catalyst at $450{ }^{\circ} \mathrm{C}$ for gasoline range hydrocarbons while Ag-ZSM-5 and Cu-ZSM-5 are better suited for light olefins production.

\section{References:-}

1. Busca, G. (2007): Acid Catalysts in Industrial Hydrocarbon Chemistry. Chemical Reviews 107 (11): 53665410.

2. Chua, Y., and P. C. Stair (2003): An Ultraviolet Raman Spectroscopic Study of Coke Formation in Methanol to Hydrocarbons Conversion over Zeolite H-MFI. Journal of Catalysis 213 (1): 39-46.

3. Follmann, S., and S. Ernst (2016): Influence of the Pore Architecture on the Selective Conversion of Ethene to Propene and Butenes over Medium Pore Zeolites. New Journal of Chemistry 40: 4414-19.

4. Hajimirzaee, S., M. Ainte, B. Soltani, R. M. Behbahani, G. A. Leeke, and J. Wood. (2015): Dehydration of Methanol to Light Olefins upon Zeolite/alumina Catalysts: Effect of Reaction Conditions, Catalyst Support and Zeolite Modification. Chemical Engineering Research and Design 93: 541-53.

5. Sassi, A., M. A. Wildman, H. J. Ahn, P. Prasad, J. B. Nicholas, and J. F. Haw. (2002): Methylbenzene Chemistry on Zeolite HBeta: Multiple Insights into Methanol-to-Olefin Catalysis. Journal of Physical Chemistry B 106 (9): 2294-2303.

6. Malley, A. J. O., A. J. Logsdail, and A. A. Sokol. (2016): Modelling Metal Centres, Acid Sites and Reaction Mechanisms in Microporous Catalysts. Faraday Discussions 188:235-255.

7. Zakaria, Z. Y., J. Linnekoski, and N. A S Amin. (2012): Catalyst Screening for Conversion of Glycerol to Light Olefins. Chemical Engineering Journal 207-208: 803-13.

8. Hadi, N., A. Niaei, S. R. Nabavi, A. Farzi, and M. Navaei Shirazi (2014): Development of a New Kinetic Model for Methanol to Propylene Process on Mn/H-ZSM-5 Catalyst Chemical and Biochemical Engineering Quarterly 28 (1): 53-63.

9. Xiaoning, W., Z. Zhen, X. Chunming, D. Aijun, Z. Li, and J. Guiyuan. (2007): Effects of Light Rare Earth on Acidity and Catalytic Performance of HZSM-5 Zeolite for Catalytic Cracking of Butane to Light Olefins." Journal of Rare Earths 25 (3): 321-28.

10. Stöcker, M. (1999): Methanol-to-Hydrocarbons: Catalytic Materials and Their Behavior. Microporous and Mesoporous Materials 29 (1-2): 3-48. 